AperTO - Archivio Istituzionale Open Access dell'Università di Torino

\title{
Why Frege Cases Do Involve Cognitive Phenomenology but Only Indirectly
}

\section{This is a pre print version of the following article:}

Original Citation:

Availability:

This version is available http://hdl.handle.net/2318/1599909

since 2016-10-09T12:01:53Z

Published version:

DOI:10.1080/13869795.2016.1176236

Terms of use:

Open Access

Anyone can freely access the full text of works made available as "Open Access". Works made available under a Creative Commons license can be used according to the terms and conditions of said license. Use of all other works requires consent of the right holder (author or publisher) if not exempted from copyright protection by the applicable law. 


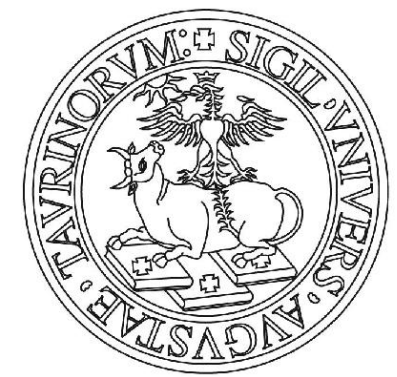

\section{UNIVERSITÀ DEGLI STUDI DI TORINO}

This is an author version of the contribution published on:

Questa è la versione dell'autore dell'opera:

"Why Frege Cases Do Involve Cognitive Phenomenology but Only Indirectly", Philosophical Explorations, 19 (2016), 205-221, $\underline{10.1080 / 13869795.2016 .1176236}$

The definitive version is available at:

La versione definitiva è disponibile alla URL:

http://www.tandfonline.com/doi/full/10.1080/13869795.2016.1176236 


\title{
Why Frege Cases Do Involve Cognitive Phenomenology but Only Indirectly
}

\author{
Alberto Voltolini \\ Department of Philosophy and Education Sciences \\ University of Turin, Italy \\ via S. Ottavio 20 - I-10124, Turin, Italy \\ alberto.voltolini@unito.it
}

\section{Abstract}

In this paper, I want to hold, first, that a treatment of Frege cases in terms of a difference in cognitive phenomenology of the involved experiential mental states is not viable. Second, I will put forward another treatment of such cases that appeals to a difference in intentional objects metaphysically conceived not as exotica, but as schematic objects, i.e., as objects that have no metaphysical nature qua objects of thought. This allows their (possibly various) nature to be settled independently of their being thought-of, in particular as concrete entities in the sense of entities that may be spatiotemporal occupiers. Yet third, as to Frege cases cognitive phenomenology may return from the back door. For the realization that, if correct, solves any such case, cannot but have a proprietary, though neither distinctive nor individuative, phenomenology. In my account, this is the realization that the different schematic intentional objects involved are none other than the same entity.

\section{Keywords}

Cognitive phenomenology, Frege cases, Gestalt properties, intentional objects, schematic objects, possibilia, ontological contraction, sameness realization 


\section{Why Frege Cases Do Involve Cognitive Phenomenology but Only Indirectly}

\section{Introduction}

In this paper, I want to hold, first, that a treatment of Frege cases in terms of a difference in cognitive phenomenology of the involved experiential mental states is not viable. Second, I will put forward another treatment of such cases that appeals to a difference in intentional objects metaphysically conceived not as exotica, but as schematic objects, i.e., as objects that have no metaphysical nature qua objects of thought. This allows their (possibly various) nature to be settled independently of their being thought-of, in particular as concrete entities in the sense of entities that may be spatiotemporal occupiers. Yet third, as to Frege cases cognitive phenomenology may return from the back door. For the realization that, if correct, solves any such case, cannot but have a proprietary, though neither distinctive nor individuative, phenomenology. In my account, this is the realization that the different schematic intentionalia involved are none other than the same entity.

\section{A treatment of Frege cases in terms of cognitive phenomenology}

Notoriously, Frege cases involve sentences of the form "a is b", where "a" and "b" are supposed to be different yet coreferential singular terms (say, "Hesperus is Phosphorus"), in order to show that such sentences have a genuine cognitive value, unlike corresponding sentences of the form "a is a", which contain two tokens of one and the same singular term thereby having 
the same referential value (say, "Hesperus is Hesperus"). As Frege said, while sentences of the latter form are trivially true, to discover that a sentence of the former form is true is to make a genuine discovery about the world. ${ }^{1}$ Mutatis mutandis, the same holds of the corresponding thoughts. While a thought of the kind that $a$ is $a$ is trivially true, a thought of the kind that $a$ is $b$, if true, amounts to a genuine discovery about the world to the effect that $a$ is the same thing as $b .^{2}$ As is well known, moreover, identity sentences or thoughts are not necessary in order to sketch a Frege case. A subject who accepts a sentence of the form "a is F" (say, "Afla is at least 5000 meters high"), while rejecting a sentence of the form "b is F" (say, "Ateb is at least 5000 meters high"), where "a" and "b" are again supposed to be different yet coreferential singular terms ("Afla" and "Ateb" in the above example), gives a different cognitive value to such sentences. ${ }^{3}$ Likewise, consider a subject who endorses a thought of the kind that $a$ is $F$ while rejecting a thought of the kind that $b$ is $F$, even if $a$ is the same thing as $b$. This subject entertains thoughts endowed with different cognitive value. Or even more radically, that cognitive difference also affects a subject who endorses a merely objectual thought about $a$ (say, Oedipus' craving Jocasta), while rejecting another such thought about $b$ (say, Oedipus' craving Mummy), when again $a$ is the same thing as $b$.

According to Kriegel (2011), one must appeal to cognitive phenomenology in order to account for the cognitive difference that Frege cases mobilize. For him, indeed, the difference in the involved thoughts is first of all a difference in phenomenology, at least when such thoughts are the mental states par excellence for him; namely, experiential states, i.e., states one is aware of. For that difference amounts to a difference in the experiential character of such thoughts, in the experiential 'what it is like' of such states. Moreover, it is a difference in cognitive phenomenology, for such thoughts differ in a nonsensory component of their experiential character. For him, on the one hand, one may indeed be aware of $a$ without being aware of $b$ even though $a$ is the same thing as $b$, insofar as one entertains different experiences of 
recognition of that thing as $a$ and of the very same thing as $b$. On the other hand, that difference in recognitional experiences is cognitive, not sensory. The two thoughts in question do not have to differ in any sensory feature. ${ }^{4}$

As to the first part of Kriegel's story, the one concerning a difference in phenomenology, it is just an episode of his overall appeal to phenomenal intentionality. The thesis that intentionality is phenomenal, or in alternative terminology experiential, says Kriegel, is the thesis that experiential mental states have their intentionality (their being about something or they having a certain, truth-sensitive, content) in virtue of their having a certain experiential character. ${ }^{5}$ Now, the fact that one can endorse a thought about $a$ while rejecting another such thought about $b$, even if $a$ is the same thing as $b$, is normally taken to show what the aspectuality feature of thoughts consists in. Roughly, thought aspectuality is the fact that a subject thinks of an object under a certain aspect, or, in an alternative formulation, as an aspect of something else. ${ }^{6}$ Moreover, aspectuality is standardly taken as constituting one of the features that characterize intentionality. ${ }^{7}$ So, it is not surprising that a believer in phenomenal, or experiential, intentionality holds that aspectuality is a matter of experiential character.

What is more characteristic is the second part of Kriegel's story, namely the fact that for him aspectuality consists in a nonsensory component of experiential character. To prove that it is so, Kriegel presents the following thought experiment. One and the same subject, he holds, can endorse an experience about Hesperus without endorsing an experience about Phosphorus even if, unlike the traditional story involving the planet Venus as seen in the evening and that planet again yet as seen in the morning, she faces Venus from the very same sensory perspective. The point is, he goes on saying, that that subject entertains a Hesperescent as well as a different Phosporescent cognitive experience of recognition, i.e., she both recognizes Venus as Hesperus and recognizes it as Phosphorus, without however realizing that it is the same thing she recognizes in such different cognitive experiences. ${ }^{8}$ 
I certainly agree with Kriegel that a Frege case involving experiential mental states must be accounted for in terms of a cognitive, not of a sensory, factor. Incidentally, to complicate the situation, unlike Kriegel's example, not even the names involved in the relevant Frege case must be different. One and the same subject can fail to realize that the object $a$ she is aware of in a certain experience is the same as the object $b$ she is aware of in another experience, even though she experiences both $a$ and $b$ from the very same sensory perspective and she names them in the same way. This is a radical variant of a Kripkean "Paderewski" case. ${ }^{9}$ The relevant subject endorses a certain experience about $a$, by naming it "Paderewski", yet she fails to endorse another experience about $b$, which is given to her under the same sensory perspective as $a$ and yet she names it again "Paderewski", for she merely has the false belief that $a$ is not the same thing as $b$ - because e.g. she entertains the paranoid general suspicion that objects may always be replaced by their Doppelgänger, or even by fakes utterly looking alike them. ${ }^{10}$

Yet pace Kriegel, this cognitive factor cannot amount to a difference in experiences of recognition. For such experiences have a perceptual nature, so that they can only differ perceptually, not cognitively. Or so I will argue.

To begin with, as Wittgenstein originally underlined, experiences of recognition are experiences that mobilize grouping properties, namely properties for the elements of the experienced item involved to be organized in a certain way, i.e., along a certain direction in a spatial dimension. Recognizing a face in certain traits, says Wittgenstein, indeed amounts to grouping such traits in a certain way, i.e., along a certain direction in a spatial dimension.

I observe a face, and then suddenly notice its likeness to another. I see that it has not changed; and yet I see it differently. I call this experience 'noticing an aspect'. $\left(2009^{4}\right.$, II xi, §113) 
I suddenly see the solution of a puzzle-picture. Where there were previously branches, now there is a human figure. My visual impression has changed, and now I recognize that it has not only shape and colour, but also a quite particular 'organization'. $\left(2009^{4}\right.$, II xi, §131)

As the previous quotations show, grouping properties are higher-order perceptual properties. Definitely, they are perceptual properties, for at least two different reasons. First, grouping properties qualify the nonconceptual content of the relevant perception. As many cases of Gestalt switches show, primarily the merely 2D ones (those that involve no pictorial perception), one can perceptually group a certain 2D figure, e.g. the so-called Mach figure, either in a certain way, e.g., as a diamond, or in another way, e.g., as a tilted square, even if one does not possess the relevant concepts. ${ }^{11}$ Second, grouping properties are responsible for many features that qualify such Gestalt switches, namely: exclusivity (the multistable percepts in a Gestalt switch are not given simultaneously), inevitability (one interpretation in that switch will eventually replace another) and randomness (the duration of one alternation in that switch is not a function of previous durations). ${ }^{12}$ Yet they are higher-order perceptual properties, for they may differ even if the basic perceptual properties - colors, shapes - remain the same. Gestalt switches again, in the cases this time not only of merely 2D ambiguous figures such as the Mach figure but also of ambiguous 3D pictures such as the duck-rabbit picture, paradigmatically show this point. In that switch, the grouping properties of the involved item's elements change even though its colors and shapes don't. As Wittgenstein remarks:

The color in the visual impression corresponds to the color of the object (this blotting paper looks pink to me, and is pink) — the shape in the visual impression to the shape of the object (it looks rectangular 
to me, and is rectangular) — but what I perceive in the lighting up of an aspect is not a property of the object, but an internal relation between it and other objects. $\left(2009^{4}\right.$, II xi, § 247) ${ }^{13}$

Hence, grouping properties make a perceptual difference in the experiences grasping them: no difference in experiences of grouping properties without a difference in the perceptual character of such experiences. Now as we have seen, experiences of recognition are other experiences where grouping properties are involved. Thus, one cannot pass from having a recognitional experience of a certain object as $a$ to having a recognitional experience of that object as $b$ without entertaining a perceptual change in one's experience: different grouping properties are there involved. Yet we have agreed with Kriegel that Frege cases involving experiential states must involve no perceptual shift. Thus, difference in experiences of recognition cannot account for such cases.

Kriegel might attempt to equate the difference in experiential character that allegedly accounts for thought aspectuality with another nonsensory component of that character. Yet that attempt must face an even more radical problem. The cognitive differential factor that Frege cases involve cannot even be a difference in cognitive experiences. Or so I will argue.

The new problem is that Frege cases can occur across both experiential and nonexperiential mental states. In other terms, one may think both occurrently and nonoccurrently of object $a$ without realizing that $a$ is the same as another object $b$ she again thinks both occurrently and nonoccurrently. One may endorse both a certain experience and a dispositional thought about $a$, and then again endorse both a certain experience and a dispositional thought about $b$, while failing to realize that $a$ is the same thing as $b$. Regardless of their being a conscious and an unconscious thought respectively, the first pair of mental states have the same aspectuality; 
likewise as to the second pair of mental states; yet the first and the second pair differ in their respective aspectuality.

Let me give an example of this situation by exploiting again a radical "Paderewski" case, where no sensory difference occurs in one's failing to recognize that (the first) Paderewski is the same as (the second) Paderewski. Suppose, first, that at a certain time a subject consciously assents to what she has unconsciously endorsed all along, namely that (the first) Paderewski is a person. In actual fact, that very endorsement has remained nonoccurrent for a long while, by merely displaying itself in the subject's own behavior, before coming at a certain point to that subject's mind. Second, suppose that, at that time, that very subject also consciously dissents from another thing she has unconsciously endorsed all along, namely that (the second) Paderewski is a person, possibly because she is caught by the paranoid general suspicion that persons can always be replaced by perceptually identical fakes. Definitely, the first pair of mental states shares a certain aspectuality, while the second pair shares another aspectuality. Yet the members of both pairs are such that one is an experiential mental state while the other is not. Thus, the cognitive factor of difference accounting for Frege cases, whatever it is, covers both experiential and nonexperiential thoughts, thereby showing that aspectuality may also occur in nonexperiential mental states.

In order to reject this conclusion, Kriegel may perform two moves. Yet neither works, as we will now see.

To begin with, Kriegel may deny that nonexperiential thoughts exhibit Frege cases, by refraining from ascribing aspectuality to such thoughts: only experiential thoughts can have aspectuality. Yet this is Searle's (1992) move he already criticized in a previous paper. ${ }^{14}$ This move is indeed implausible: relevant differences in agential behavior may well depend on the 
agent's having different nonexperiential thoughts that she fails to recognize as involving the same thing.

The above radical "Paderewski" case already shows this point. In failing to recognize that (the first) Paderewski is the same thing as (the second) Paderewski, the subject in question acts differently on the basis of her unconscious endorsement on the one hand and of her unconscious failure of endorsement on the other hand. Yet the point may also be shown by appealing to unconscious perceptions. Let me suitably adapt a real example involving pictures and heminegligent subjects, i.e., persons who fail to consciously perceive what they face in the lefthand side part of their visual field. ${ }^{15}$ Suppose that one such subject faces a house when its lefthand side is burning and then faces the same house again when no burning occurs at all (see the following two figures), while however supposing for some reason that she faces different things, so that a new house has replaced the previous one.
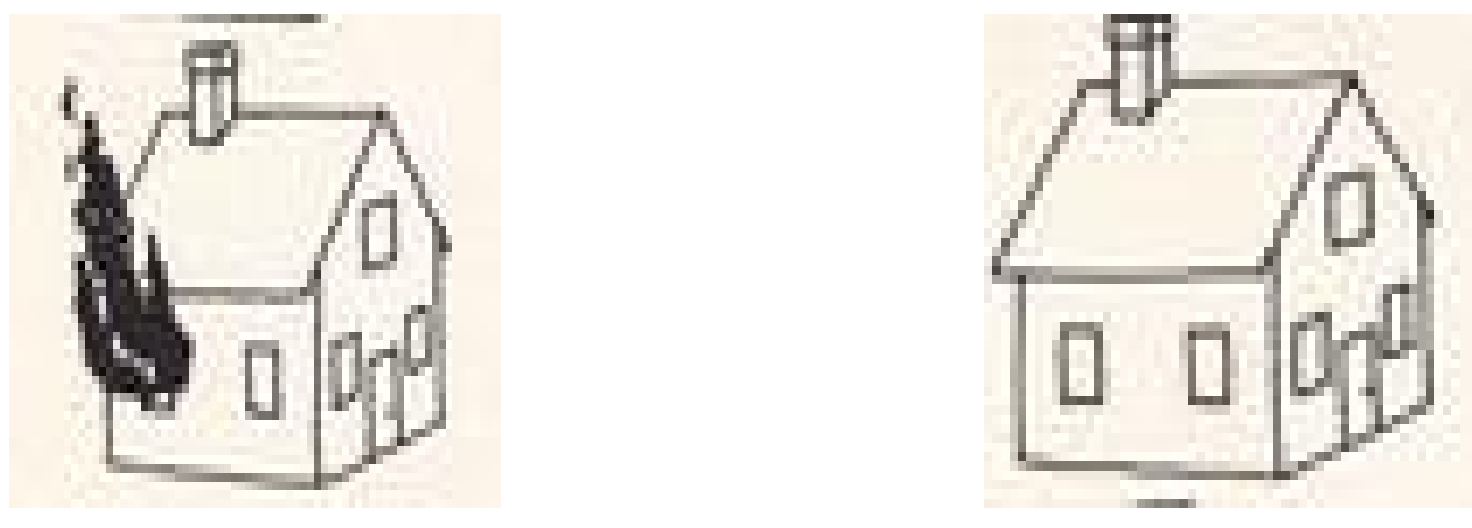

If one asked to that subject whether she sees differences in what she perceives (actually, the same house), she would negatively answer the question: she consciously grasps only the righthand sides of the house(s), which ex hypothesi make no difference in her visual field. As far as her aware perception is concerned, she indeed sees no difference. Yet if that subject is asked in which house she would like to live, she answers (what she takes to be) the second house, the non-burning one. Thus, she unconsciously grasps the differences in aspectuality her two perceptions mobilize. 
On second thought, that aspectuality is indifferent to awareness is not astonishing at all. For aspectuality has not to do with subjective perspective - basically, how objects phenomenally look to subjects - but rather with objective perspective - how objects are given from geometrical points of view, from the points of origin of the involved perceptions (or other mental states) occurring in the relevant subject. Indeed, objective perspective has nothing to do with the phenomenal look of an object that qualifies one's experience of it, for it rather captures the so-called outline shape of an object, i.e., the solid angle circumscribed by the straight lines one can trace from the perceiver's ideal eye to an object's contours. ${ }^{16}$ Definitely, outline shape is a mind-dependent property, for if one changes the point of origin from which one grasps something, the outline shape of that very something changes as well. Yet this mind-dependence is a weak, not a strong, form of dependence. For outline shape is also an objective property, it is a property of the experienced objects, insofar as it has nothing to do with any phenomenal feature concerning how that something looks to a subject; in particular, there is nothing particularly visual in outline shape. ${ }^{17}$ Now, differences in outline shape definitely affect differences in aspectuality. In a very famous example, a coin that is elliptical from one objective perspective, i.e., that has a certain outline shape, may not be recognized as the same thing that is round from another such perspective, i.e., that has another outline shape. ${ }^{18}$ So, aspectuality may be possessed by unconscious perceptions that are still entertained from geometrical points of view, from certain points of origin. In the above example, even if the point of origin is fixed, the house a subject faces is given to her under different contours - the flamed vs. the nonflamed one - that determine the different outline shapes that are traced from that very point to that house.

At this point, Kriegel may try to perform the second move I hinted at, i.e., to deny that the same cognitive factor of difference accounts both for experiential and nonexperiential thoughts. 
Yet the above radical "Paderewski" case shows that even that move is doomed to fail. For in that case there is an anaphoric link we have no reason not to take at face value - one consciously assents to WHAT one unconsciously believed - which suggests that the aspectuality of the relevant experiential thought (the one involving (the first) Paderewski, viz. Paderewski from that perspective) is the same as the aspectuality of the relevant nonexperiential thought (the one involving again (the first) Paderewski, viz. Paderewski from the very same perspective). Mutatis mutandis, the same holds as to the conscious dissent and the unconscious disbelief concerning (the second) Paderewski, viz. Paderewski from the other perspective.

In order to defend his second move, following Searle (1992) Kriegel might reply that in the above pairs the first member of the pair, the nonoccurrent thought, has a derived aspectuality, while the second member of the pair, the occurrent thought, has original aspectuality. Since the former thought is unconscious, it borrows its aspectuality from the latter thought, which bears aspectuality on its sleeves - just as a picture of Hesperus borrows its aspectuality from an experience of Hesperus, and likewise for a picture and an experience of Phosphorus. ${ }^{19}$

Yet even if we allowed for that difference between an occurrent and a nonoccurrent thought which is rather controversial - this would not determine the cognitive difference between a conscious and an unconscious mental state Kriegel is looking for. For he should acknowledge that it is the same property, the same aspectuality, that the two thoughts in question share, by simply being ascribed to them in different ways. As always happens not only as far as original vs. derived aspectuality are concerned, but also as far as any original $F$ vs. derived $F$ are concerned. A king instantiates regality by her own sake; a vice-king instantiates regality because it is conventionally ascribed to her. Yet the two Majesties instantiate the very same property, regality, though in different ways. Mutatis mutandis, the same holds of original and derived aspectuality. 
Kriegel may try to counter this objection by applying to original vs. derived aspectuality what he says concerning original vs. derived intentionality in general. For him, original and derived intentionality can indifferently be taken either as different properties or as different modes of entertaining the very same property, intentionalilty. For, he says, such accounts are interdefinable: having such different properties is the same as having a genus, intentionality, in different ways. ${ }^{20}$ So, having intentionality in the derived way is for a thought the same as having a certain property, while having intentionality in the original way is for a thought to have another property. Mutatis mutandis, the same should hold of aspectuality.

Yet this rejoinder does not work. For taken as a mode difference, the difference between original and derived $F$, whatever $F$ is, is not a difference in the ways for $F$ to be possessed, but rather in the ways for $F$ to be ascribed. Thus, for $F$ to be derived is not the same as for something to possess a species of a more general property.

\section{From cognitive experiences to intentional objects}

My previous distinction between subjective and objective perspective actually gestures towards a general reason as to why Kriegel's strategy to account for Frege cases does not work. That strategy attempts at reconstructing a Fregean difference of modes of presentation between experiences as a difference in terms of manners of presentation of such experiences, notably as a difference in the experiential character of such experiences. Yet, as Chalmers (2004) originally noted, one cannot account for a difference of modes in terms of a difference of manners. On the one hand, manners of presentation concern the modality of an experiential mental state. Insofar as that state is experiential, they have to do with the subjective matter of 
how the state with its experiential features presents itself to its subject, by displaying to her certain worldly properties - by letting them have, within that subject's experience, a phenomenal look. On the other hand, modes of presentation concern an objective matter of that state, insofar as they can be traced back to objective perspectives viz. outline shapes of the experienced objects.

It is now wise to look for other strategies in order to account for the cognitive difference that thoughts involved in the Frege cases mobilize. An interesting alternative is to treat modes of presentation in terms of mental files. Nowadays, this strategy seems in the literature to be highly appealing. A mental file is supposed to be a nondescriptive repository which, when appropriately labeled with a certain mental tag, stores information about an object in a subject's mind. ${ }^{21}$ If one appeals to mental files, one can account for Frege cases as follows. A subject opens different mental files that however are, unbeknownst to her, related to the very same object. For instance, in the normal Hesperus-Phosphorus case, a subject opens both a certain file about Venus that in her mind is labeled "Hesperus" and contains the information being the evening star and another file again about Venus that in her mind is labeled "Phosphorus" and contains the information being the morning star. She however fails to know that both files are about the same object, Venus. When that subject comes to know that Hesperus is Phosphorus, she merges the two files into a new single one that is labeled "Venus" and contains information coming from those files. Or more cautiously - for one may always wonder whether that sameness really holds - she keeps both files yet she links the information contained in either file to that of the other file. ${ }^{22}$

In the above way, this strategy accounts for the difference in cognitive value that Frege cases involve without appealing at all to differences in cognitive phenomenology. In this, I think that the strategy is on the right track. Nevertheless, I wonder whether it is altogether correct. For if we come back to the Frege case I sketched before, the above radical "Paderewski" case, it is 
hard to account for the difference in question in terms of a difference in mental files. For in that case the two mental files allegedly in question not only contain exactly the same information but they are also labeled in the same way - "Paderewski". ${ }^{23}$ A believer in mental files might perhaps reply that the files are nevertheless different for they are opened in different times. Yet even this feature of the story is not essential. One may reconceive the situation in question as involving a deluded subject whose present perception is hallucinatorily split in two, so that she assumes at one and the same time that she confronts herself with two perfectly alike Paderewskis, while not even being able to distinguish those guys by locating them in different portions of the space she is facing. She merely wonders whether the (first) Paderewski she seems to see at a certain time is the same as the (second) Paderewski she seems to see at that very time even if, as to those Paderewskis, there is no bit of information that differs. ${ }^{24}$ More problematically, the subject's coming to know that (the first) Paderewski is the same as (the second) Paderewski cannot be accounted for either in terms of file merging or in terms of file linking. For, since the information that the two files should contain is allegedly the same, there is neither merging nor linking of that information. The only justification one has in that case for holding that different files are opened is just that the subject involved assumes that she deals in her thoughts with different objects. So, why not taking straightforwardly this assumption into account ${ }^{25}$

Indeed, I take that this radical "Paderewski" case reveals so to speak the essence of Frege cases, what all such cases have in common. So, in order to be able to account for such cases, one must be able to account for this very case. Now, as I just hinted at, if one reflects more carefully on that case, it turns out that the only relevant cognitive difference around is that the involved subject takes her first thought to be about a different entity from the entity she takes her second thought to be about. ${ }^{26}$ Thus, why don't we take that assumption seriously, by holding that the entity the subject is firstly thinking about is really different from the entity she is secondly 
thinking about? In order to do that I will suppose, first, that the subject in question really entertains different intentional objects in her thoughts, and second, that once she comes to know the truth about her cognitive situation, what she discovers is that those intentionalia are (in some sense) nothing but the same thing.

In order to make this supposition plausible, two moves must be performed. First, I must appeal to a satisfying metaphysical conception of what an intentionale is; that is, a conception that does not fall under those approaches that appeal to differences in intentionalia in terms of differences in problematic Meinongian objects, or any other sort of bizarre entities: exotica, in Sainsbury's (2010) terms. As we will see, thata metaphysical move has certain ontological consequences. Second, in order to legitimately say that different intentionalia are discovered to be the same thing, I must mobilize a notion of sameness that is both different from and weaker than the ordinary notion of identity. Let me consider these two moves in turn.

To begin with, following Crane (2001), I take that an intentionale is a schematic object: that is, the object a thought is directed upon that has no metaphysical nature insofar as it is thoughtof. According to this characterization, an intentionale is not a metaphysically peculiar Meinongian object, nor any metaphysically bizarre entity either. Rather, it is an object whose metaphysical nature, if any, is settled independently of the fact that that object is thought-of. In this respect, it may turn out that different intentionalia have different natures. ${ }^{27}$ For instance, in mentally contemplating Elizabeth II one may think both of the present UK Majesty and of number Two. Both Elizabeth II and number Two are intentionalia of such thoughts insofar as they simply are what those thoughts are directed upon. Qua schematic intentionalia, they have no metaphysical nature insofar as they are thought-of. This does not prevent them from having a nature independently of their being thought-of. Actually, that nature is a very different one respectively: the first object is a concrete entity, a person, the second object is an abstract entity, a number. 
This metaphysical way of putting things has an ontological consequence. In the overall domain of what there is, we find just those intentionalia whose nature is such that we are ontologically committed to entities of that nature. The thoughts that are about intentionalia whose nature is such that we are not committed to objects of that nature involve no relation at all to those objects, for there really are no such objects. If one is thinking both of Elizabeth II and of her Freudian superego, one may say that her thought is directed upon to both Elizabeth and her superego, for both are the intentionalia of that thought. Yet in the overall domain of what there is we allow for concreta but not for superegos, which are just false scientific posits having incompatible determinations (e.g., having both a neural realization and no such realization). Thus, we are ontologically committed to Elizabeth, for her Majesty is a concretum, but we are not so committed to her superego, for it is just such a false theoretical posit. ${ }^{28}$

In particular, among the entities we are ontologically committed to there are mere possibilia, i.e., entities that do not actually exist even though they might have existed. ${ }^{29}$ For, as Cocchiarella (1982) maintained, both mere possibilia and actual possibilia, possible entities that actually exist, are entities of the same metaphysical nature: namely, concreta again, i.e., entities that may be spatiotemporal occupiers. If this is the case, to allow for actual possibilia while dispensing with mere possibilia is just false parsimony. ${ }^{30}$

As we will now see, in fact, the above metaphysico-ontological move sets the stage in order for me to perform my second move, namely, to understand the Frege cases in terms of a difference in schematic intentionalia that are however also such that may be discovered to be (in some sense) the same. To begin with, the schematic intentionalia that are involved in the Frege cases turn out precisely to be mere possibilia. Now, if one appeals to schematic intentionalia that are mere possibilia, one may indeed appeal to a difference in such objects in accounting for Frege cases. For what primarily happens in Frege cases is that in facing a certain entity, one thinks both of a certain schematic intentionale $a$ that is a certain mere possibile and 
of another schematic intentionale $b$ that is another mere possibile. This way of putting things matches appearances: for the subject involved, her thoughts are about different objects.

Yet moreover, the above way of putting things immediately prompts the following question: what happens when one comes to know that a certain schematic intentionale $a$ is the same as another schematic intentionale $b$ ? For me, what is involved here is an aspectuality resolution, in that the objects in question appear to be mere aspects of another object, where aspectuality is basically conceived in the terms seen in the previous Section; namely, they appear to be mere outline shapes of another object. In a nutshell, the former objects are none other than the latter object. Now, let me take this last way of talking seriously: being for some schematic intentionalia to be none other than another object is for the former objects to stand in a certain relation of sameness with the latter object that differs from ordinary identity. In other and more detailed terms, one has to understand the relation for some schematic intentionalia of being none other than another object that aspectuality resolution involves as a relation of ontological contraction that is both different from and weaker than ordinary identity.

To begin with, ontological contraction is a many-one relation, in that it may involve more than one object as its first relatum, just one object as its second relatum: either one or infinitely many schematic intentionalia may ontologically contract itself/themselves to another object. In Frege cases that we would intuitively consider as cases of disguised identity, as when one discovers that (pretending that the story is true) Batman is Bruce Wayne, we have only two objects involved, where the former is a schematic intentionale that ontologically contracts itself to the latter. In the normal Frege cases, such as the standard Hesperus-Phosphorus one, we have two schematic intentionalia, Hesperus and Phosphorus, which ontologically contract themselves to a third object, the planet Venus. Yet nothing prevents us from imagining further, more complicated, cases in which the objects involved are more than three: e.g. a case in which a subject not only thinks of Hesperus and Phosphorus but also of Meridius, the noon star, and 
of Postmeridius, the afternoon star, by finally discovering that not only Hesperus and Phosphorus, but also Meridius and Postmeridius are none other than Venus.

A definition of ontological contraction is now in order. An object(s) is (are) none other than another object iff i) the former object(s) fail(s) to exist(s) even if it (they) might, while the latter object exists, even if it might not; ii) for any contingent, existence-entailing and individual property (i.e., a property that cannot be exemplified by more than one object at a given time), which could be falsely attributed to the former object(s) in the erroneous conviction that it (they) existed, this property is possessed either by the latter object or by nothing.

As a consequence of this definition, all the objects involved by ontological contraction are possibilia, hence concreta according to the aforementioned characterization. Yet the left-hand side relata of ontological contraction are mere possibilia, for they do not actually exist although they might have existed, while the only right-hand side relatum of that relation is an actual possibile, for it actually exists.

In the above definition, moreover, clause i) accounts for the contingency of the relation. In a possible unactual world in which a certain actually nonexistent schematic intentionale exists, it is ontologically contracted to nothing else. It may be the case e.g. that our different actually nonexistent schematic intentionalia Hesperus and Phosphorus exist; in the possible world this supposition mobilizes, they do not ontologically contract to Venus at all.

As is well known, for Kripke the possibility that Hesperus is not the same as Phosphorus is an epistemic possibility. Yet not only, as Kripke acknowledges,${ }^{31}$ it is an epistemic possibility that is also the metaphysical possibility that sketches a possible world is which a given subject is in the identical epistemic status as she is in the actual world, but for the fact that she is confronted there with an objectual triad Hesperus - Phosphorus - Venus. But also, the epistemic states there involved are identical with the actual ones for they precisely mobilize the very same 
schematic intentionalia. Those schematic intentionalia, Hesperus and Phosphorus do not actually exist for they here ontologically contract themselves to Venus. Yet they exist in that possible world, while entertaining there no ontological contraction with Venus.

To be sure, one might wonder whether the merely possible objects that are involved in that metaphysical possibility are respectively identical with the nonexistent objects the relevant subject actually thinks about. One might rather say that the two cognitively identical crossworld situations mobilize, for the subject involved, the very same epistemic states as in the actual world, respectively having just the very same narrow, non-'object involving', content, which in the possible world in question respectively picks out a new item existing there: the first state has a narrow content that picks out a certain Hesperus there, the second state has another narrow content that picks out a certain other Phosphorus there. In other words, that subject crossworldly represents things in the same way, by entertaining the very same, nonrelationally individuated, content in each such representations respectively, even though by means of them she faces a new existing something (a different one respectively) in that possible world. Yet once I allow for intentionalia as schematic objects, we need no appeal to the theoretical notion of narrow content. The cognitive identity involved both by the actual and by the possible situation may be grasped in terms of the respective identity in the schematic intentionalia that are both actually thought about although they do not actually exist and are possibly perceived, so that they exist merely possibly. One actually thinks of the Hesperus that possibly perceives; likewise as to Phosphorus. Clearly enough, if supposing that Hesperus is not Phosphorus were to suppose that Venus is not identical with itself, that supposition would not amount to a metaphysical possibility at all, as Kripke stresses: there is no chance for an object not to be identical with itself. ${ }^{32}$ But pace Kripke, this is not the supposition in question.

Furthermore, clause ii) of the above definition accounts for the aspectuality of a contracted schematic intentionale. As to all the contingent, existence-entailing and individual properties 
that were ascribed to a schematic intentionale in the erroneous conviction that it existed, they either belong to the existent object that schematic intentionale is ontologically contracted to or belong to nothing. Moreover, given i), this aspectuality is just apparent; in worlds where a schematic intentionale is not contracted to another object, the worlds in which it exists, it does not even appear to be an aspect of that object (or of any other object for that matter).

According to this definition, ontological contraction is not only different from ordinary identity, as its being a many-one relation already shows, but it is also weaker than ordinary identity, for it is not an equivalence relation.

Firstly, ontological contraction is neither reflexive nor symmetric. For an entity cannot contract itself to itself, on pain of existing and nonexisting at the same time. Nor, if an entity contracts itself to another entity, does the latter contract itself to the former, for the very same reason: symmetry would require that both entities existed and did not exist at the same time. Secondly, the relation is certainly transitive, but only vacuously. If $a$ is none other than $b$ and $b$ is none other than $c$, then $a$ is none other than $c$, yet one of the two conjuncts in the above antecedent is false, so that the very antecedent is false as well. For if $a$ is none other than $b$, then $b$ exists, so it is not the case that $b$ is none other than $c$; whereas if $b$ is none other than $c$, then it does not exist, so it is not the case that $a$ is none other than $b$.

Granted, this account of the Frege cases evokes some Meinongian accounts of them. According to such accounts, the known fact that $a$ is $b$ mobilizes a sameness relation that involves different intentionalia and is weaker than identity. This relation is either a relation of consubstantiation - different Meinongian objects are consubstantiated as facets of the very same massive entity (Castañeda 1989) - or a relation of coexemplification - different Meinongian objects are exemplified by the very same ordinary individual (Zalta 1988), where Meinongian objects respectively are either one-one correlates of property sets or something 
like Platonic attributes. In the Hesperus-Phosphorus case, we would thus have either that the Meinongian object the morning star is consubstantiated with the different Meinongian object the evening star as facets of the same massive object, Venus, or that the first Meinongian object and the second Meinongian object are coexemplified by an ordinary individual, Venus.

Clearly, such Meinongian accounts of the Frege cases have the same explanatory strength as my present account, for they also take appearances at face value. For all such accounts, a subject correctly thinks that her first thought is about a different thing from what her second thought is about, insofar as she really entertains different intentionalia in such thoughts.

Yet metaphysically speaking the intentionalia that are involved in the Meinongian accounts are Meinongian entities, exotica in Sainsbury's sense, not schematic objects as those I am appealing to here. Thus, my account is better than those ones, for in accepting it one does not have to endorse a bizarre metaphysics. One simply has to allow from an ontological point of view for mere possibilia. For as I said before, the schematic intentionalia that are involved as left-hand side members of the relation of ontological contraction metaphysically are possible entities that simply do not actually exist. Yet, since such entities belong to the same metaphysical kind as actual possibilia, for all of them are concreta, to dispense with them would be false parsimony. ${ }^{33}$

\section{Cognitive phenomenology comes back from the rear door}

Whatever the merits of the above account, Frege cases involving experiential states turn out not to be explained in terms of a difference in cognitive phenomenology. Does this mean that cognitive phenomenology has nothing to do with those cases? Not quite. That phenomenology 
is indirectly involved by these cases. For one's (possibly mistaken) ${ }^{34}$ realization that $a$ is the same as $b$ cannot be an unconscious thought, but it amounts to an 'aha'-experience (in the terms Mulligan 1988 made popular) of a cognitive kind. ${ }^{35}$

The argument as to why realizing that $a$ is the same as $b$ cannot be an unconscious thought is simple. First, that realization prompts a behavioral change in the realizing subject. Consider what happened to poor Oedipus when he realized that Jocasta was the same as Mummy. Second, that change must fall under report awareness, for it is not a change prompted by internal unconscious drives. Imagine again Oedipus' noticing that he is no longer sexually attracted by Jocasta, but he does not know why. Here we have a behavioral change that may well depend on some Oedipus' internal, unconscious, change in his conative dispositions. Yet this is not the kind of change that follows his realization that Jocasta is the same as Mummy. For the first kind of change requires in the subject affected by it no stance as to the sameness of the individual responsible for that change, while the latter kind of change requires a subject to realize that what were two things turn out in some sense to be one. In order for that realization to be performed, it must be an aware one. ${ }^{36}$

Now, if that realization has a phenomenally cognitive import, what kind of import is it? David Pitt $(2004,2011)$ has maintained that a cognitive phenomenology must be proprietary - a sui generis one, proper to occurrent thoughts rather than to other kinds of mental experiential states - distinctive - distinct types of occurrent thoughts have distinct cognitive phenomenal properties - and individuative - in virtue of its having the experiential properties it has, the occurrent thought having it has a specific intentional content. Is this the case also with our realizations of sameness?

To begin with, the first feature, proprietaryness, is certainly ascribable to our sameness realizations. As I said, they are 'aha'-experiences. In this respect, their cognitive 
phenomenology is a sui generis one, to be told not only from the different forms of sensory phenomenology but also from the different forms of cognitive phenomenology that feelings, moods or other sorts of cognitive states may involve.

Yet moreover, the second feature, distinctiveness, is hardly ascribable to such realizations. Granted, different experiences of the same sensory genus - say, different exteroceptive experiences in the same sensory modality (e.g., gustatory sensations), different proprioceptive experiences of the same general kind (e.g., kinaesthetic sensations), and different interoceptive sensations of the same general kind (e.g., different pains) instantiate different kinds of such sensations insofar as they are felt differently, as Pitt says. ${ }^{37}$ Yet by hypothesis no such qualitative feeling is involved in realizing that, say, Hesperus is the same as Phosphorus, vs. realizing that, say, Jocasta is the same as Mummy, for we have acknowledged that, whatever it is, one such realization is not sensory. Then how can we ground the idea that such realizations are typologically distinctive? There is no relevant parameter of similarity between the above sensory cases and the nonsensory cases of sameness realizations in order for the argument by analogy Pitt implicitly appeals to go through. If sensations of different kinds are phenomenally different, so are sameness realizations of different kinds, insofar as the latter are phenomenally similar to the former, Pitt seems to argue. Yet since the former have a qualitative phenomenology that the latter lack, there is no real phenomenal similarity between the former and the latter.

Quite on the contrary, another model naturally suggests itself that involves no distinctiveness for the sameness realizations. Consider e.g. the nonsensory feeling of awakeness. One may feel of being awake now, and one may again feel of being awake a minute from now. Yet such different temporal locations prompt no phenomenal difference in the 'what it is like' of the feeling of awareness: one just still feels to be awake - unlike, say, when one is going to fall asleep, where that feeling dims up to its complete evaporation. Likewise, although as far as 
their intentional propositional content is concerned, realizing that, say, Hesperus is the same as Phosphorus is quite different from realizing that, say, Jocasta is the same as Mummy - in my account, different schematic intentionalia are respectively involved - the two realizations have the same experiential character. Granted, I have here implicitly relied on another argument by analogy: if nonsensory feelings of different kinds are phenomenally identical, so are sameness realizations of different kinds, insofar as the latter are phenomenally similar to the former. Yet that argument may work, for the compared experiences share the relevant similarity parameter; namely, their both being phenomenally nonsensory.

Finally, if the above is the case, then of course the phenomenology of our realizations cannot even be ascribed the third feature, individuativity. For the very same experiential character rather corresponds to different intentional propositional contents of the occurrent thoughts involved, sameness realizations in this case. Thus, it cannot obviously account for their having the different content they have. ${ }^{38}$

Pitt would reply that his main argument in favour of his claim that the cognitive phenomenology here involved is proprietary as well as distinctive and individuative appeals to the kind of introspective acquaintance with an occurrent thought - in our case, a sameness realization - that enables one to be immediately aware of that thought. According to this argument, one is able to identify via that acquaintance an occurrent thought as the thought it is (that is, one is able not only to distinguish it from any other occurrent mental states she entertains, her other occurrent thoughts included, but also to identify it as the particular thought it is endowed with a certain intentional content). Yet one could not be so able unless that thought had a cognitive phenomenology that is not only proprietary, but also distinctive and individuative. Hence, that thought has that phenomenology. ${ }^{39}$ 
Yet in order for this argument to go through, one has again to rely on a disputable analogy between occurrent thoughts and sensory mental states. True enough, in order to identify via immediate awareness a sensory mental state as the state it is, one must be able to grasp the qualitative phenomenological property that makes it different from any other such state. When sipping a glass of Burgundy, one can identify via introspective acquaintance her present headache while simultaneously telling it from her kinaesthetic sensation affecting her lips as well as from her tasting that wine. For such immediate awareness of that headache is the awareness of the qualitative phenomenological property that makes that headache the sensory state it is. Now, let us well suppose that in being introspectively acquainted with an occurrent thought, one grasps the nonqualitative phenomenal property that thought admittedly has. Yet it is not in virtue of that grasping that she immediately identifies that thought, unless it has been already established that it is precisely that property that makes that thought differ from any other occurrent thoughts of hers, rather than a different property, typically its having the intentional content it has. Yet this was what the argument was supposed to prove. ${ }^{40}$

To see the point, consider the following case. Russell once thought that one may be immediately aware of universals. ${ }^{41}$ If this were true, then the fact that one is immediately aware, say, of the Bold as different from the Beautiful would have to do not with the phenomenological properties, if any, that are involved in the first and in the second awareness respectively, but rather with what makes the Bold be a different universal from the Beautiful. Mutatis mutandis, the same holds as to occurrent thoughts in general and to our sameness realizations in particular. If what essentially constitutes the realization that Jocasta is the same as Mummy and the realization that Laius is the same as Daddy that poor Oedipus discovered at one and the same time is their respective different intentional propositional contents, the fact that Oedipus identifies via introspective acquaintance the first realization as different from the second has to do not with the proprietary phenomenology of such realizations, which is admittedly identical, 
but with the distinct intentional propositional contents of such realizations that make such realizations be different thoughts. ${ }^{42}$

Let me take stock. Frege cases involving experiential mental states cannot be straightforwardly accounted for in terms of a difference of cognitive phenomenology. The cognitive difference they mobilize can be alternatively accounted for in terms of a difference in the schematic intentionalia the relevant mental states are about. Yet realizing that such objects are the same, which to me has to be accounted for in terms of a relation of sameness that is both different and weaker from ordinary identity, does involve cognitive phenomenology. For that realization must involve an 'aha'-experience endowed with such a phenomenology of a proprietary kind. ${ }^{43}$

\section{References}

Bayne, T. and Montague, M. 2013. "Cognitive Phenomenology: An Introduction." In Cognitive Phenomenology, edited by T. Bayne and M. Montague, 1-30. Oxford: Oxford University Press.

Block, N. 2014. "Seeing-As in the Light of Vision Science." Philosophy and Phenomenological Review 89: 560-572.

Budd, M. 1987. "Wittgenstein on Seeing Aspects.” Mind 96: 1-17.

Castañeda, H-N. 1989. Thinking, Language, and Experience. Minneapolis: University of Minnesota Press.

Chalmers, D. 2004. "The Representational Character of Experience." In The Future for Philosophy, edited by B. Leiter, 153-181. Oxford: Oxford University Press.

Chudnott, E. 2015. Cognitive Phenomenology. London: Routledge. 
Cocchiarella, N. 1982. "Meinong Reconstructed Versus Early Russell Reconstructed.” Journal of Philosophical Logic 11: 183-214.

Crane, T. 2001. Elements of Mind. Oxford: Oxford University Press.

Crane, T. 2013. The Objects of Thought. Oxford: Oxford University Press.

Crimmins, M. 1998. "Hesperus and Phosphorus: Sense, Pretense, and Reference." The Philosophical Review 107: 1-47.

Fodor, J. 2010. LOT 2: The Language of Thought Revisited. Oxford: Oxford University Press. Frege, G. 1980³. “On Sense and Reference.” In Translations from the Philosophical Writings of Gottlob Frege, edited by P.T. Geach and M. Black, 56-78. Oxford: Blackwell.

Frege, G. 1997. “Letter to Philip Jourdain, Jan. 1914.” In The Frege Reader, edited by M. Beaney, 319-322. Oxford: Blackwell.

Geach, P.T. 1976. “Two Kinds of Intentionality?” The Monist 59: 306-320.

Hopkins, R. 1998. Picture, Image and Experience. Cambridge: Cambridge University Press. Kriegel, U. 2003. “Is Intentionality Dependent Upon Consciousness?” Philosophical Studies 116: 271-307.

Kriegel, U. 2011. The Sources of Intentionality. Oxford: Oxford University Press.

Kripke, S. 1971. "Identity and Necessity." In Identity and Individuation, edited by M.K. Munitz, 135-164. New York: New York University Press.

Kripke, S. 1979. “A Puzzle about Belief.” In Meaning and Use, edited by A. Margalit, 239283. Dordrecht: Reidel.

Kripke, S. 1980. Naming and Necessity. Oxford: Blackwell.

Kroon, F. 2001. "Fictionalism and the Informativeness of Identity." Philosophical Studies 106: $197-225$.

Jagnow, R. 2011. “Ambiguous Figures and the Spatial Contents of Perceptual Experience: A Defense of Representationalism.” Phenomenology and the Cognitive Sciences 10: 325-346. 
Lewis, D. $1986^{2}$. Counterfactuals. Oxford: Blackwell.

Lewis, D. 1986. On the Plurality of Worlds. Oxford: Blackwell.

Marshall, J.C., and P.W. Halligan 1988. "Blindsight and Insight in Visuo-Spatial Neglect." Nature 336: 766-767.

Meinong, A. [1916] 1972. Über Möglichkeit und Wahrscheinlichkeit. In Gesamtausgabe bd. VI. Graz: Akademische Druck- und Verlagsanstalt.

Mulligan, K. 1988. “Seeing As and Assimilative Perception.” Brentano Studies 1: 129-152.

Newall, M. (2011). What is a Picture? Basingstoke: Palgrave.

Noë, A. (2004). Action in Perception. Cambridge MA: The MIT Press.

Orlandi, N. 2011. "Ambiguous Figures and Representationalism.” Phenomenology and the Cognitive Sciences 10: 307-323.

Peacocke, C. (1992), A Study of Concepts. Cambridge MA: The MIT Press.

Pitt, D. 2004. "The Phenomenology of Cognition or What Is It Like to Think That P?" Philosophy and Phenomenological Research 69: 1-36.

Pitt, D. 2011. "Introspection, Phenomenality and the Availability of Intentional Content." In Cognitive Phenomenology, edited by T. Bayne and M. Montague, 141-172. Oxford: Oxford University Press.

Raftopoulos, A. 2009. Cognition and Perception. Cambridge MA: The MIT Press.

Raftopoulos, A. 2011. “Ambiguous Figures and Representationalism.” Synthese 181: 489-514. Recanati, F. 2012. Mental Files. Oxford: Oxford University Press.

Russell, B. 1912. The Problems of Philosophy. Cambridge: Home University Library.

Sainsbury, M. 2010. "Intentionality without Exotica." In New Essays on Singular Thoughts, edited by R. Jeshion, 300-317. Oxford: Oxford University Press.

Sainsbury, M., and M. Tye 2012. Seven Puzzles of Thought and How to Solve Them. Oxford: Oxford University Press. 
Schellenberg, S. (2008). “The Situation-Dependency of Perception.” Journal of Philosophy 105: 55-84.

Searle, J.R. 1992. The Rediscovery of the Mind. Cambridge MA: The MIT Press.

Shani, I. 2007. "Consciousness and the First Person." Journal of Consciousness Studies 14: $57-91$.

Voltolini, A. 2007. "How to Allow for Intentionalia in the Jungle." Russell 27: 86-105.

Voltolini, A. 2013. "There Are Intentionalia of Which It Is True That Such Objects Do Not Exist.” International Journal of Philosophical Studies 21: 394-414.

Voltolini, A. 2014. "Contingent Sameness and Necessary Identity." In Castañeda and his Guises, edited by A. Palma, 197-211. Berlin: De Gruyter.

Voltolini, A. 2015. A Syncretistic Theory of Depiction. Basingstoke: Palgrave.

Wettstein, H. 1988. “Cognitive Significance without Cognitive Content.” Mind 97: 1-28.

Wettstein, H. 1989. “Turning the Tables on Frege Or How Is It That 'Hesperus Is Hesperus' Is Trivial?” Philosophical Perspectives 3: 317-339.

Wittgenstein, L. 1980. Remarks on the Philosophy of Psychology I-II. Oxford: Blackwell.

Wittgenstein, L. 2009 ${ }^{4}$ Philosophical Investigations. Oxford: Blackwell.

Zalta, E.N. 1988. Intensional Logic and the Metaphysics of Intentionality. Cambridge MA: The MIT Press.

\footnotetext{
${ }^{1}$ Cf. Frege $\left(1980^{3}, 56\right)$.

${ }^{2}$ For this application of Frege cases to thoughts, cf. Sainsbury and Tye (2012, 2-4).

${ }^{3}$ Cf. Frege (1997, 320-1).

${ }^{4}$ Cf. Kriegel $(2011,127-9)$. This difference in experiential character must be for Kriegel further analyzed either in relational terms (as a self-representational experiential character) or in monadic terms (by appealing to adverbialism). Here I will not discuss these further aspects of Kriegel's proposal.

${ }^{5}$ Cf. Kriegel $(2011,43-4)$.
} 
${ }^{6}$ The first standard formulation of aspectuality, or aspectual shape, is e.g. in Crane (2001, 25-30). Yet one may find the second, less standard, formulation in Geach (1976, 314-7). This formulation traces back at least to Meinong ([1916] 1972). As we will see in the next Section, there are reasons to consider the second formulation as better fitting the phenomenon at issue.

${ }^{7}$ Cf. Crane $(2001,25-30)$.

${ }^{8}$ Cf. Kriegel $(2011,128)$.

${ }^{9}$ For the original case, cf. Kripke (1979).

${ }^{10}$ For cases going in this direction, cf. originally Wettstein $(1988,25 \mathrm{fn} .51)$.

${ }^{11}$ These switches merely involve what Wittgenstein called optical aspects. Cf. (1980, I, §§ 970, 1017). For the idea that grouping properties constitute the nonconceptual content of the relevant perception, see e.g. Jagnow (2011), Orlandi (2011), Raftopoulos (2009, 2011) and my own Voltolini (2015).

${ }^{12}$ Cf. Block (2014, 567).

${ }^{13}$ See also Budd (1987,6,15-6)

${ }^{14} \mathrm{Cf}$. Kriegel (2003). For a different criticism of Searle's position underlying that also unconscious mental states can be aspectual cf. Shany (2007).

${ }^{15}$ The original case is presented by Marshall and Halligan (1988).

${ }^{16} \mathrm{Cf}$. Hopkins (1998). Outline shape is what the aesthetic tradition has called, following Alberti, "visual pyramid". A very similar notion is the notion of occlusion shape, i.e., the shape that, once it is projected on a plane lying between the perceiver and the picture's subject, prevents that perceiver from seeing that subject by utterly occluding it. For this notion cf. Hyman (2006).

${ }^{17}$ For this distinction between a weak and a strong form of mind-dependence cf. originally Newall $(2011,67)$. Once one allows for this distinction, one may say that outline shape is the basic form of what Schellenberg (2008) labels situation-dependent properties, which she takes as mind-independent properties just because she actually has only strongly mind-dependent properties in mind. In actual fact, Schellenberg herself compares her situationdependent properties with Noë's (2004) P-properties and Peacocke's (1992) scenes, which are precisely genera of outline shapes.

${ }^{18}$ Cf. Hopkins (1998, 59-60), Hyman (2006, 78-9).

${ }^{19}$ For this conception of original and derived intentionality, cf. Kriegel (2011, chap.4).

${ }^{20}$ Cf. Kriegel $(2011,207)$.

${ }^{21}$ For that characterization of a mental file, cf. e.g. Recanati (2012). 
${ }^{22}$ For this account of Frege cases, cf. again Recanati (2012, chap.4).

${ }^{23}$ Recanati $(2012,40-1)$ presents a case, the Cicero-Tully case, which however presents the first feature - shared information - but not the second feature - shared label.

${ }^{24}$ This case is similar to the puzzle of the two tubes Sainsbury and Tye discuss in $(2011,14-5)$.

${ }^{25}$ In (2010), Fodor holds that there is a difference grounding the postulation of distinct mental files in that case, namely the fact that such files have different Mentalese labels. Yet troubles with Mentalese aside, there is no justification for that move. As Fodor himself remarks, that move is appealed in order to disambiguate distinct tokens of the very same natural language expression that refer to different items. Yet since according to him the relevant different tokens of the natural language expression "Paderewski" corefer, why should they correspond to different Mentalese labels?

${ }^{26}$ As Wettstein $(1988,24-5),(1989,333-4)$ originally envisaged.

${ }^{27}$ As Crane (2001, 15-7) acknowledges.

${ }^{28}$ Crane $(2001,2013)$ draws the (metaphorical) divide between intentionalia we are ontologically committed to and those we are not so committed in a different way, namely, by appealing to existence: intentionalia we are not really committed to are all the nonexistent ones. Yet for me this is not the right way to draw that divide. For pace Crane $(2013,68)$, we may be ontologically committed to intentionalia whose thought-independent nature is not existence-entailing. As we will immediately see, mere possibilia are a case in point. See my Voltolini (2013).

${ }^{29}$ As Lewis (1986) originally maintained.

${ }^{30}$ On this see my Voltolini (2007). See also Lewis himself $\left(1986^{2}, 84\right)$.

${ }^{31}$ Cf. Kripke (1971, 157fn.15), (1980, 103-4, 143).

${ }^{32}$ Cf. Kripke (1980, 103-5, 109).

${ }^{33}$ For more about this solution of the Frege cases, see my Voltolini (2014). Both Crimmins (1998) and Kroon (2001) differently allow for the idea that the objects a subject thinks about in a Frege case are somehow not identical with the only object that actually exists in that case. Yet they think that this this nonidentity is just a fictional, not a real, possibility.

${ }^{34}$ One can misrecognize that $a$ is the same as $b$ when, in my terms, no ontological contraction of such objects to a further one occurs.

${ }^{35}$ For a (possibly not exhaustive) list of 'aha'-experiences, cf. indeed Mulligan (1988). 
${ }^{36}$ Recanati $(2012,47-50,84-8)$ admits that there is a distinction between judgements of identity and presuppositions of identity, for only the former can be experienced while the latter can be subpersonal. Yet he does not notice that the former involves a relation of sameness different from and weaker than ordinary identity.

${ }^{37}$ Cf. Pitt $(2004,13,31),(2011,143)$.

${ }^{38}$ Bayne and Montague acknowledge that the fact that cognitive phenomenology has proprietaryness, which they take as the defining feature of that phenomenon, does not entail that it also has the other features. Cf. $(2011,12-$ 3). Granted, failure of distinctiveness for sameness realizations does not involve that cognitive phenomenology is not distinctive in general. There may be cases of cognitive phenomenology that involve distinctness, e.g. experiences (as) of understanding. Yet I cannot deal with this issue here.

${ }^{39}$ Cf. Pitt $(2004,7-25)$.

${ }^{40}$ For a similar criticism see Chudnoff, who however also worries whether occurrent thought have proprietaryness. Cf. $(2015,37,41)$.

${ }^{41}$ Cf. e.g. Russell (1912).

${ }^{42}$ Pitt would rejoinder that, unlike universals, occurrent thoughts are mind-dependent objects $(2004,22)$. This may be true, but it still fails to entail that to be immediately aware of mind-dependent occurrent thoughts means to identify them by means of their nonsensory phenomenological properties rather than by means of their intentional contents.

${ }^{43}$ I presented preliminary versions of this paper at the conferences Phenomenology of Cognitive Experiences, University College Dublin, Nov 5-7 2014, Dublin; Mind and Consciousness, Università Vita-Salute S. Raffaele, Jan 8 2016, Milan. I thank Elisabetta Sacchi for some insightful comments. 